
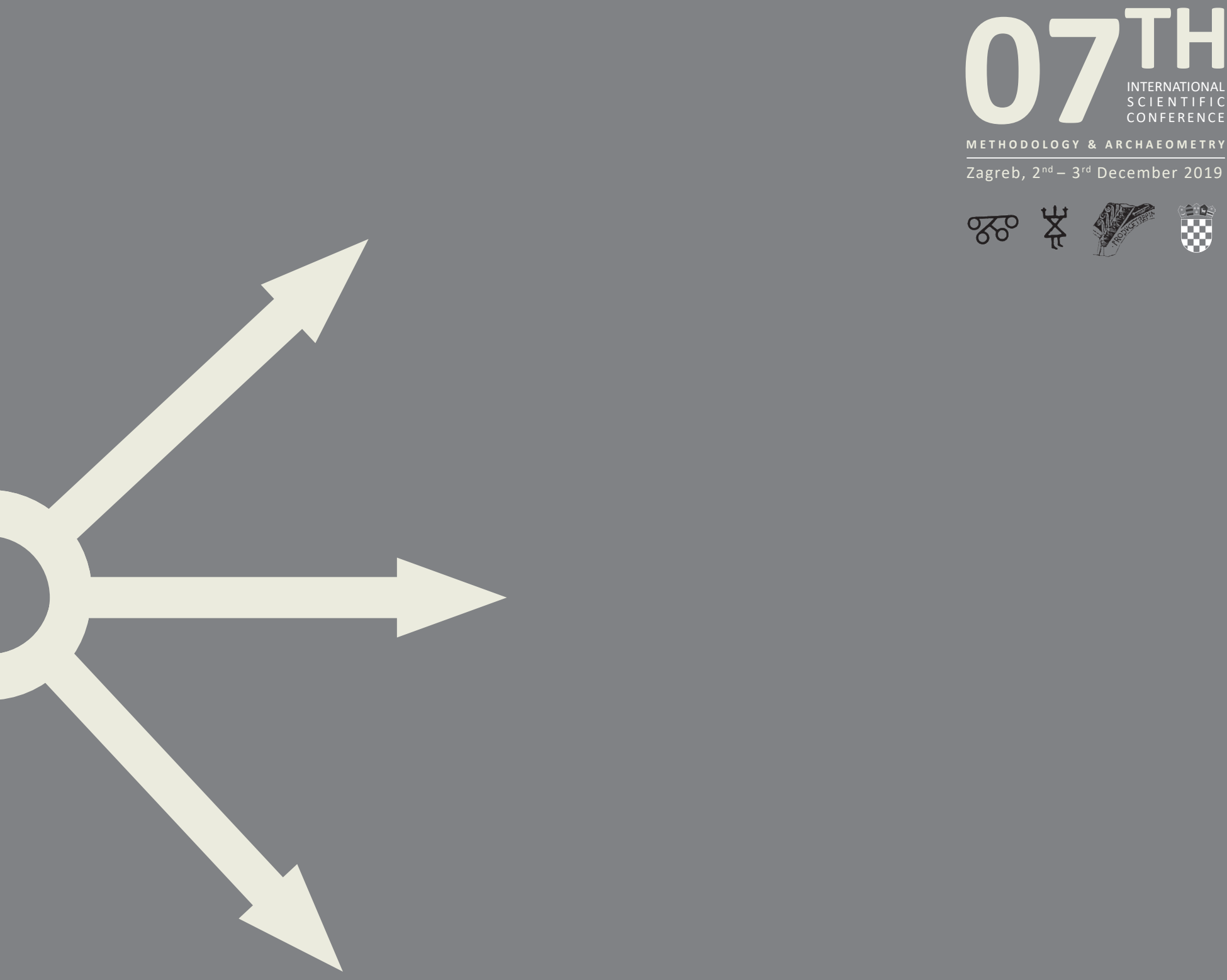
\%ㅇㅇ 岗

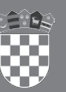
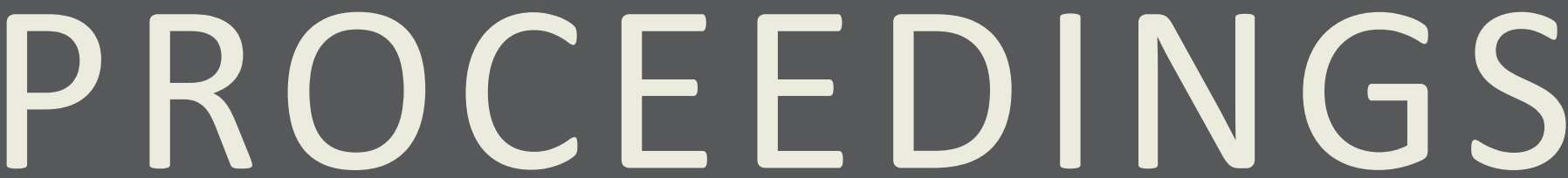

FROM THE $7^{\text {TH }}$ SCIENTIFIC CONFERENCE METHODOLOGY AND ARCHAEOMETRY 


\section{IMPRESSUM}

PUBLISHER

Faculty of Humanities and Social Sciences, University of Zagreb

FOR THE PUBLISHER

Miljenko Šimpraga

EDITOR

Ina Miloglav

Faculty of Humanities and Social Sciences, University of Zagreb

EDITORIAL BOARD

Predrag Novaković

Faculty of Arts, University of Ljubljana, Slovenia

Dimitrij Mlekuž

Faculty of Arts, University of Ljubljana

\& Centre for preventive archaeology, Ljubljana, Slovenia

Michela Spataro

The British Museum, London, United Kingdom

Duska Urem-Kotsou

Democritus University of Thrace, Komotini, Greece

Jasna Vuković

Faculty of Philosophy, University of Belgrade, Serbia

Rajna Šošić Klindžić

Faculty of Humanities and Social Sciences, University of Zagreb, Croatia

Jacqueline Balen

Archaeological Museum in Zagreb, Croatia

DESIGN \& DTP

Srećko Škrinjarić

All papers were reviewed in the peer review process in which the identity of both reviewers and authors, as well as their institutions, are respectfully concealed from both parties.

DOI

https://doi.org/10.17234/METARH.2020

ISSN 2718-2916

Faculty of Humanities and Social Sciences of the University of Zagreb

URL

https://openbooks.ffzg.unizg.hr/index.php/FFpress/catalog/series/MetArh http://www.ffzg.unizg.hr/metarh/

Publishing of this e-book is supported by

Ministry of Science and Education of the Republic of Croatia any medium or format, as long as they give appropriate credit, provide a link to the license, and indicate if changes were made. The content of this publication may not be used for commercial purposes. If the publication is remixed, transformed, or built 

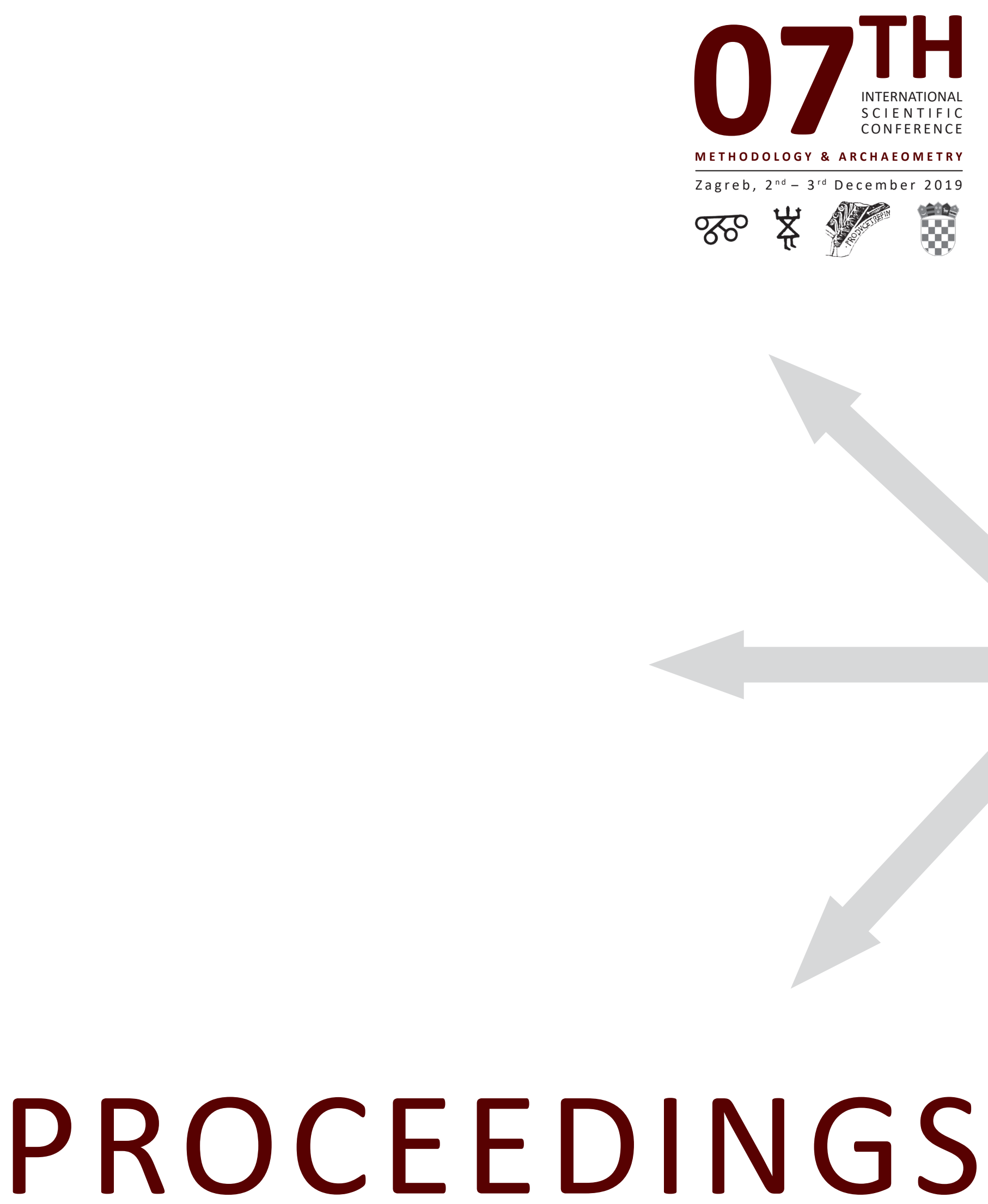

FROM THE $7^{\text {TH }}$ SCIENTIFIC CONFERENCE METHODOLOGY AND ARCHAEOMETRY 


\section{Content}

Ina Miloglav

Preface

Tamara Leskovar

09 Laboratory-based research on the changes caused to the in situ preserved archaeological remains by the heavy equipment compaction

Cornelius Meyer, Saša Kovačević, Daria Ložniak Dizdar, Mario Gavranović, Rajna Šošić-Klindžić, Tomislav Hršak, Marko Dizdar, Hrvoje Vulić, Boris Kratofil

Patterns everywhere: Geophysical prospection strategies at archaeological sites in Northern and Eastern Croatia

Domagoj Tončinić, Vinka Matijević, Miroslav Vuković

Image-based modeling approach in documenting Early Christian memorial chapel in Velić, Croatia

Esmeralda Agolli

A discussion on the theoretical and methodological ramifications of classification and typology of archaeological material: a Perspective from the Late Prehistoric Pottery (Albania)

Katarina Šprem

All aboard! Quarries and transport in Roman Istria 


\title{
Laboratory-based research on the changes caused to the in situ preserved archaeological remains by the heavy equipment compaction
}

\author{
Tamara Leskovar
}

https://doi.org/10.17234/METARH.2020.02

\author{
Tamara Leskovar \\ University of Ljubljana \\ Faculty of Arts \\ Department of Archaeology \\ Zavetiška 5 \\ SI - 1000 Ljubljana \\ tamara.leskovar@ff.uni-lj.si
}

\begin{abstract}
When planning the in situ preservation of archaeological remains, one of the issues that need consideration are changes in the physical environment and their impact on the remains. This includes mechanical loading of the surface above the site and its consequences on the various layers and artefacts within the site. The contribution represents a laboratorybased experiment on the effects of heavy equipment compaction on archaeological remains. A set of tests was performed to understand better the changes that mechanical loading of the surface will cause to the archaeological site. In a custom-made steel case, artificial archaeological sites were created by layers of sandy silt and gravel, in which a variety of archaeological and modern artefacts were placed. To measure stress and strain, some of the artefacts were equipped with strain gauges. A servo-hydraulic piston was used to simulate static and dynamic mechanical loading. Moisture and temperature were recorded before, during and after each test. At the same time, the three-dimensional recording of the artefacts and layers, and soils stiffness measurements were performed before and after each loading.

The obtained data allowed us to study the compression of layers and their moisture, movements of the artefacts, stresses and strains on the artefacts, and the macroscopically observable damage of the artefacts caused by loading. We were able to deduce how big of an influence grain size and moisture of the soil have, how important the type of material representing archaeological remains and their position within the soil is, that movements of the artefacts within the layers are also an important factor to consider, that vibrations are far more damaging than force alone, and that protective layer is not always best preservation strategy. With the presented results, our research has been a step towards a better understanding of the effects of heavy equipment compaction to archaeological remains and thus to the preservation of archaeological sites in situ.
\end{abstract}

Keywords: in situ preservation of archaeological sites, laboratory tests, heavy equipment compaction, strain gauges, artefact deformation

\section{Introduction}

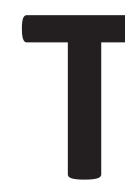
The in situ preservation of archaeological remains is based on the idea that the remains are best preserved in their original environment. It allows for holistic and long-term preservation of the remains in their place of origin, where they continue to form an integral part of the local environ- ment and are thus most valuable. It is grounded on the facts that properly executed archaeological excavation is time-consuming, logistically and financially demanding process which physically destroys the integrity of the archaeological record; that technological development will allow us to obtain more and better information with 
less damage to the remains; that heritage needs to be preserved for the future generations; and that under the right circumstances the in situ preservation is a viable option (Groenewoudt and Bloemers 1997: 128). Following the Valletta Convention (Council of Europe 1992), the integrated and long-term preservation of the remains in situ is thus a priority. However, it is often overlooked that even under ideal conditions and with the proper management, the process of degradation of the remains cannot be stopped, only slowed down (Huisman 2009: 181). Also, increasing human interventions are constantly changing the environment, further jeopardizing the long-term preservation of the remains (Darvill and Fulton 1998). Thus, the in situ preservation of archaeological remains represents a double-edged sword.

On the one hand, it offers the possibility of integrated and long-term preservation of the remains. At the same time, simultaneously increases the risk of complete destruction and loss of unique information about our heritage. Another set back in the state of research. Due to the complexity of the filed with various materials and their degradation paths under different conditions, research is expensive, logistically and methodologically demanding, time-consuming and still in its beginnings.

One of the multiple factors that need to be considered when deciding for a long-term in situ preservation of the remains is the impact of the environment in which the remains are preserved (Huisman 2009: 181). This includes imposed stressed caused by additional surface loading (e.g. heavy equipment and/or embankments). Previous research has already shown that stress in the soil is a major issue when dealing with proper preservation of the remains (Garfinkel and Lister 1983; Olson et al. 1988; Mathewson et al. 1992; McGowan and Prangnell 2015). In general, the additional surface load increases stress in the soil, which causes deformation and relocation of the soil particles, the expulsion of the air and/or water from the voids, and thus compression of the soil layers. The resulting settlement affects the archaeological site in various ways. The most obvious are displacement and deformation of the remains (Das and Sobhan 2013), which changes their original context and physical form. Settlement can also alter the stratigraphy, especially if the site consists of diverse materials, behaving differently under the imposed stress (de Lange et al. 2012; McGowan and Prangnell 2015). Furthermore, the loss of pore water and more tightly organised soil particles can lead to moisture changes, especially dangerous for organic remains (de Lange et al. 2012).
In the context of archaeological remains, the behaviour of various soil types under the imposed mechanical stress was studied by Hyde (2004), Sidell et al. (2004) and Avsenik (2012), while limited research also included the behaviour of the buried artefacts (Garfinkel and Lister 1983; Olson 1989; Mathewson et al. 1992; Godwin et al. 2009; McGowan and Prangnell 2015). Even though from different perspectives and various methodological procedures, results highlighted depth, orientation and type of the buried remains, soil moisture and grain size distribution, and type of the imposed load as the most influential factors. However, tangible data on how additional stress affects archaeological remains in the ground are very limited. Our research aimed to contribute towards a better understanding of the loading effects on the subsurface archaeological sites above the groundwater level. The main objective was to develop a useful methodological procedure while gathering new data on the behaviour of various materials and soil layers under loading.

\section{Methodology}

The artificial archaeological site was established in a $0.85 \times 0.85 \times 1.2 \mathrm{~m}$ steel box with perforated bottom for the water drainage. The lower layer was composed of gravel and upper of sandy silt. Layers were $0.4-0.45 \mathrm{~m}$ thick, installed gradually, through $0.05-0.1 \mathrm{~m}$ thick sublayers. During installation, each sublayer was compacted by trampling with a load of $\sim 4.5 \mathrm{kN} / \mathrm{m}^{2}$. Modern and archaeological artefacts were buried in soil layers. In tests, $1-3$ wooden plates and piles were installed vertically and horizontally in sandy silt. In test 4-9 metal, glass, bone and ceramic artefacts were deposited in sandy silt and gravel (Fig. 1). Some of the artefacts were equipped with strain gauges. ${ }^{1}$ The gauges were attached to the surface of an artefact, perpendicular to the imposed surface load (Fig. 2). To avoid potential damage, gauges were covered with $\sim 3 \mathrm{~mm}$ thick layer of modelling clay and the wires were placed into the rubber hose. Since the artefacts were buried in the soil and thus the orientation of the principal axes was unknown, rosette strain gauges (WFLA-6-11-5L) were used (Fig. 2) so that strain

\footnotetext{
${ }^{1}$ Only modern artefacts were equipped with strain gauges. The decision was made based on the limited finances and thus number of relatively expensive strain gauges, combined with better comparability of the data among unaltered modern materials in comparison to the already changed and thus variously preserved archaeological materials.
} 
was recorded in three separate directions $\left(0^{\circ},+45^{\circ}\right.$, $45^{\circ}$ ). Moisture (Decagon 10HS Large Volume VWC) and temperature (Decagon RT-1) sensors were positioned approximately $10 \mathrm{~cm}$ below and $10 \mathrm{~cm}$ above the specimens in the sandy silt. Sensors were not used in gravel
Loading of the surface was performed with a servohydraulic piston, provided with $0.82 \times 0.82 \mathrm{~cm}$ steel panel (Fig. 3), $2-12$ days after the preparation of the site. The exception was test 9, in which the site was soaked with water and left for 4 months for partial con-
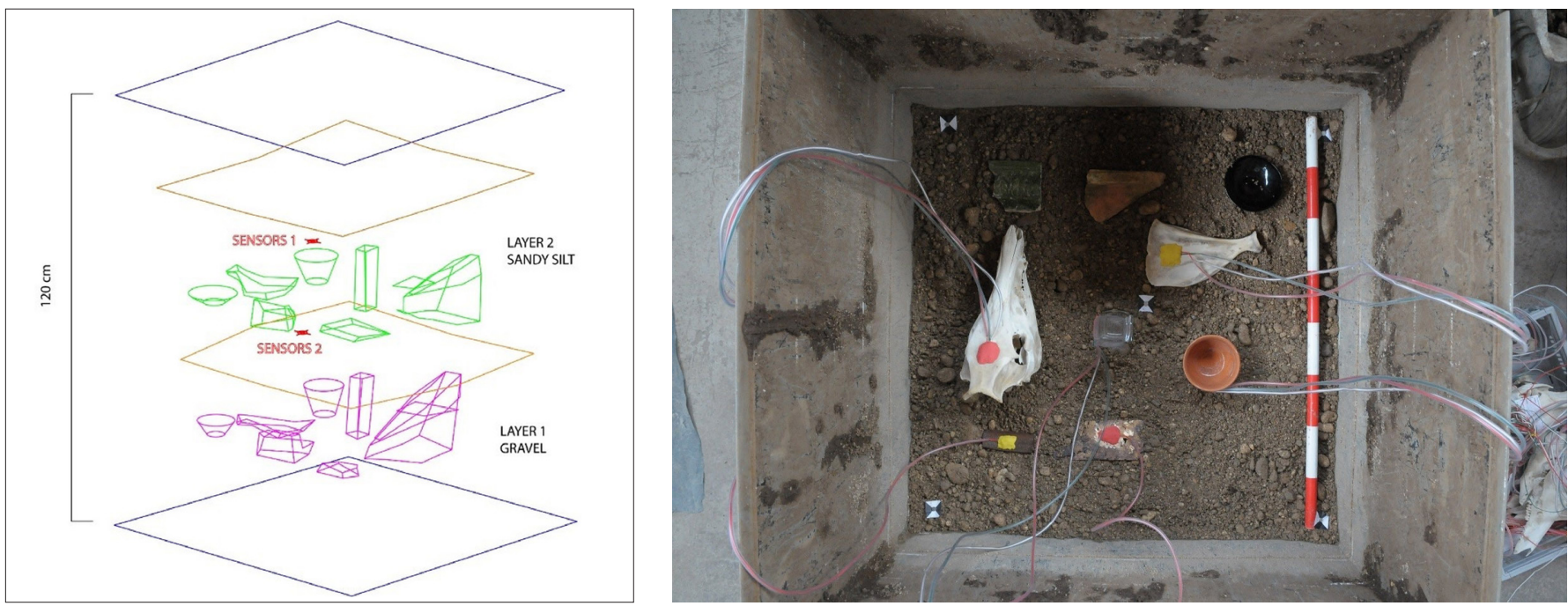

Figure 1. Schematic presentation of the artificial archaeological site (left) and an example of the specimens in gravel (right).
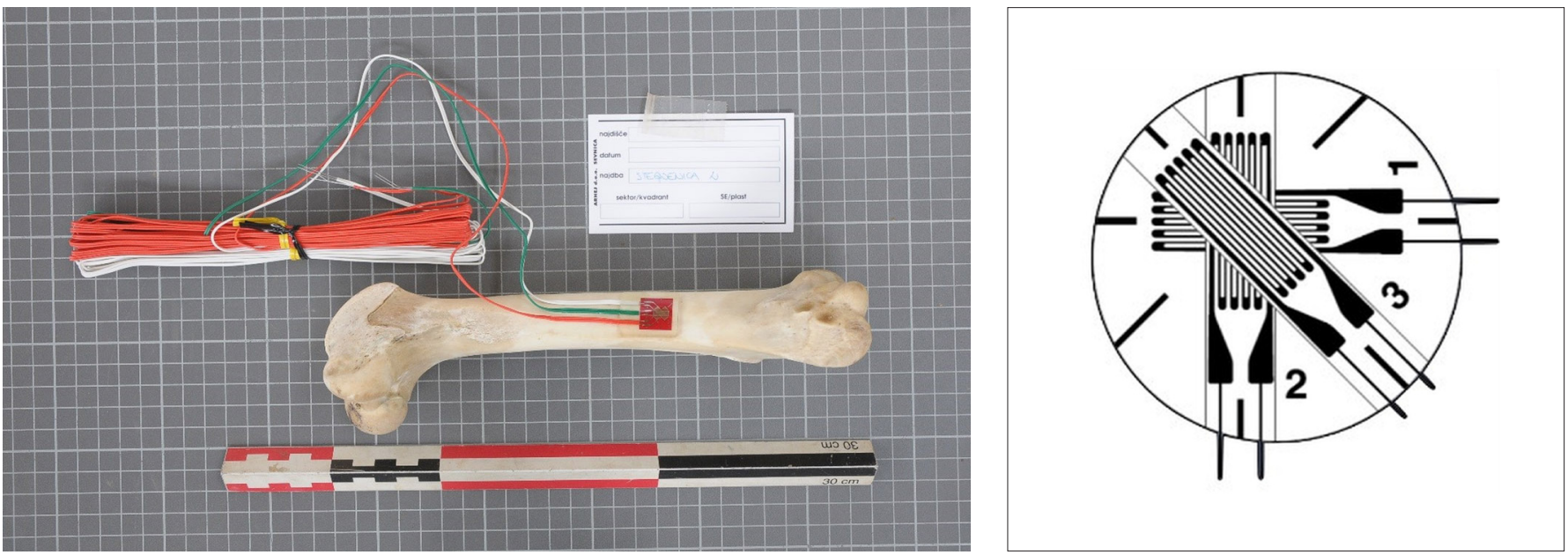

Figure 2. Artefact (femur of a pig) equipped with a strain gauge (left) and rosette strain gauge composition (right).

as it is too coarse to retain water and could also damage the sensors. The spatial position of artefacts and the uppermost surface of each layer were recorded with electronic tachymeter. solidation. Loading in six tests was monotonic, whereas in three tests it was dynamic. In monotonic tests force was applied gradually, through $20 \mathrm{kN}$ increments up to the maximum force of $160 \mathrm{kN}$ (surface load $250 \mathrm{kN} / \mathrm{m}^{2}$ ). 
The applied force was maintained for 300 seconds after each increment (Fig. 4). In the dynamic tests, $20 \mathrm{kN}$ increments reached up to the maximum force of $100 \mathrm{kN}$ (surface load $150 \mathrm{kN} / \mathrm{m}^{2}$ ). The applied force was maintained for only 100 seconds, with $6 \mathrm{~Hz}$ vibrations added (Fig. 5). In the first six tests, $0.25 \mathrm{~m}$ thick protective layer of geotextile and crushed stones were put before loading (Table 1).

Before, during and after loading, temperature sensor, moisture sensor and dilatometer probe were used to determine temperature, moisture and stiffness for settlement prediction of the sandy silt (constrained modulus). Sensors and probe were not used in gravel as it is too coarse and thus not suitable for the tests.

Additional test 10 was performed, comparing the behaviour of archaeological and modern bones and ceramic in the exact same loading conditions. In a $40 \times 30 \times 50 \mathrm{~cm}$ big box a $0.45 \mathrm{~m}$ thick layer of sandy silt was installed with ceramic fragments (modern, roman, prehistoric) and animal bones (modern, roman) positioned $20 \mathrm{~cm}$ deep in the layer. In this test, all the artefacts were equipped with strain gauges. The surface of the sandy silt was covered with a wooden plate to spread the load on the layer equally. Monotonic loading was performed until failure of the artefacts occurred. During loading applied force and strain on the artefacts were recorded.

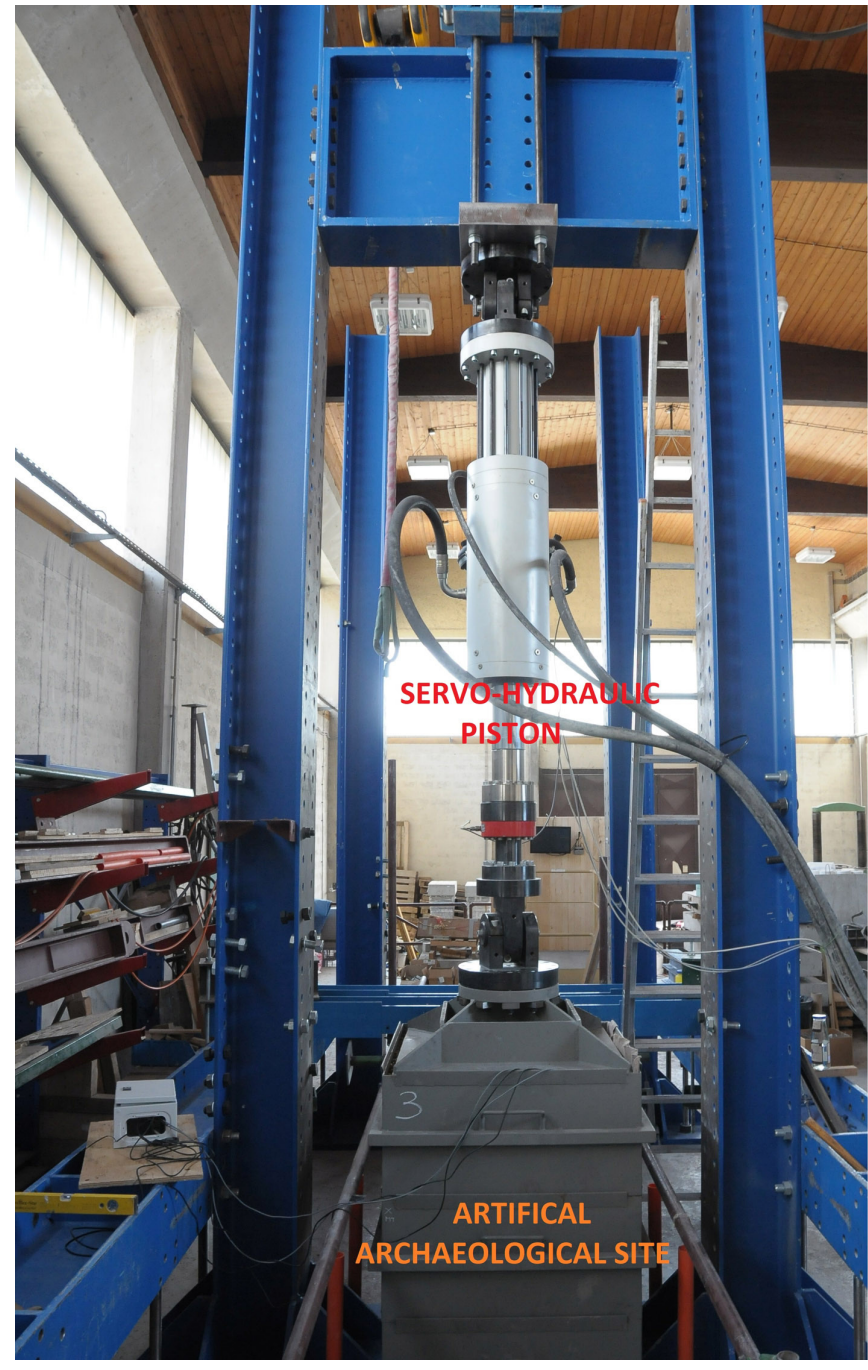

Figure 3. Servo-hydraulic piston and metal box with the artificial archaeological site.

Figure 4. Graphs representing monotonic (left) and dynamic (right) loading.
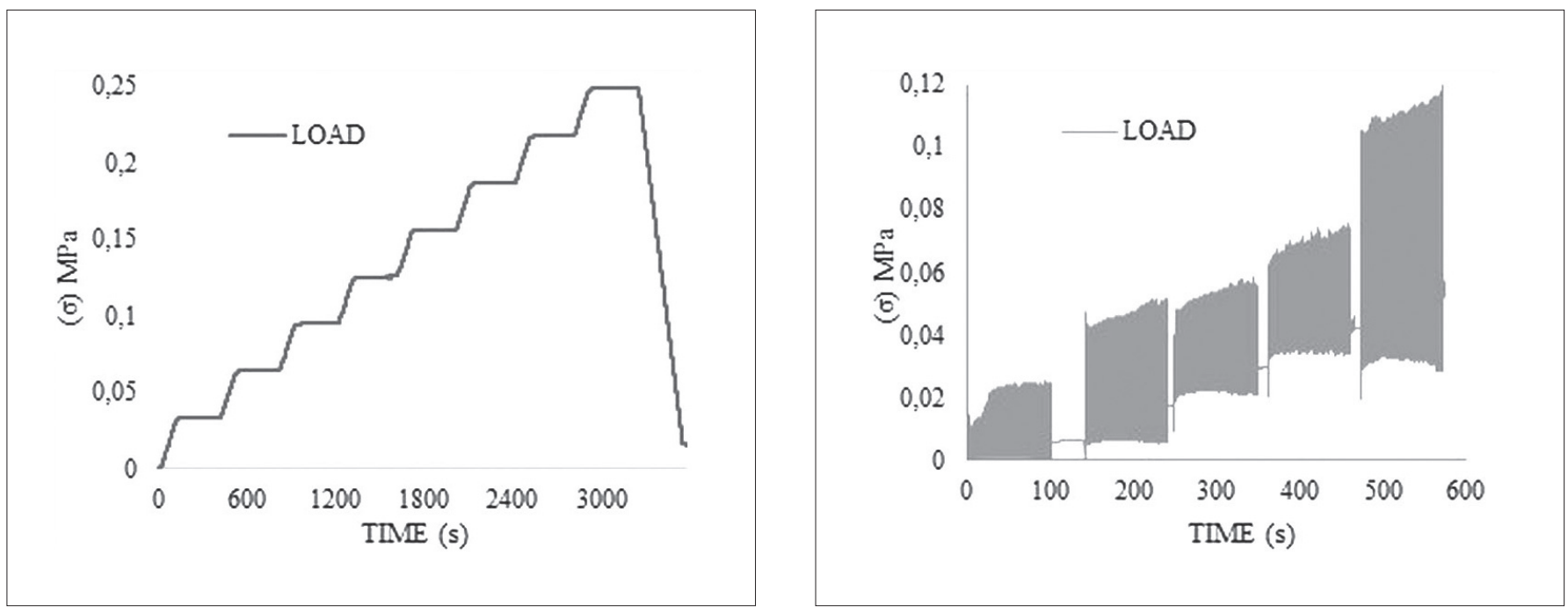


\begin{tabular}{|c|c|c|c|c|c|}
\hline TEST \# & ARTEFACTS & MOISTURE & PROTECTION & CONSOLIDATION & LOADING \\
\hline 1 & Wood & $22 \%$ & Y & 7 days & $\mathrm{M}$ \\
\hline 2 & Wood & $22 \%$ & Y & 4 days & M \\
\hline 3 & Wood & $22 \%$ & Y & 6 days & D \\
\hline 4 & Ceramic, bones, glass, metal & $21 \%$ & Y & 2 days & M \\
\hline 5 & Ceramic, bones, glass, metal & $21 \%$ & Y & 12 days & M \\
\hline 6 & Ceramic, bones, glass, metal & $19 \%$ & Y & 5 days & D \\
\hline 7 & Ceramic, bones, glass, metal & $19 \%$ & $\mathrm{~N}$ & 5 days & M \\
\hline 8 & Ceramic, bones, glass, metal & $19 \%$ & $\mathrm{~N}$ & 5 days & $\mathrm{D}$ \\
\hline 9 & Ceramic, bones, glass, metal & $18 \%$ & $\mathrm{~N}$ & 4 months & M \\
\hline 10 & Bone, ceramic & / & $\mathrm{N}$ & none & M \\
\hline
\end{tabular}

Table 1. Summary of the characteristics and loading conditions in each test.

After each loading and unloading, excavation and documentation of the site were performed, following archaeological methodological standards as much as possible.

During loading and unloading, strain gauges were measuring strain on the artefacts. Based on the recorded strains minimal $\left(\varepsilon_{\min }\right)$ and maximal $\left(\varepsilon_{\max }\right)$, principal strains were computed using the following equations:
Using bulk unit weight $(\gamma)$ of gravel and sandy silt, their thickness ( $\mathrm{z}$ ), vertical force applied to the surface (q) and $\mathrm{I}_{3}$ coefficient (Das and Baranja 2012: 337), stress in the soil at a depth of the artefacts during loading $\left(\sigma_{\text {LOAD }}\right)$ was calculated:

$$
\begin{aligned}
& \varepsilon_{\text {min }}=\frac{1}{2}\left[\varepsilon_{1}+\varepsilon_{2}-\sqrt{2\left\{\left(\varepsilon_{1}-\varepsilon_{3}\right)^{2}+\left(\varepsilon_{2}-\varepsilon_{3}\right)^{2}\right\}}\right], \\
& \varepsilon_{\max }=\frac{1}{2}\left[\varepsilon_{1}+\varepsilon_{2}+\sqrt{2\left\{\left(\varepsilon_{1}-\varepsilon_{3}\right)^{2}+\left(\varepsilon_{2}-\varepsilon_{3}\right)^{2}\right\}}\right] .
\end{aligned}
$$

$$
\begin{aligned}
& \gamma=\frac{\text { WEIGHT }}{\text { VOLUME }}, \\
& \sigma=\gamma * z, \\
& \Delta \sigma=q * I_{3}, \\
& \sigma_{L O A D}=\sigma+\Delta \sigma .
\end{aligned}
$$

With the addition of Young's modulus ( $E$ ) and Poisson's ratio (v) of each artefact material, principal stresses were calculated. Minimal $\left(\sigma_{\min }\right)$ and maximal $\left(\sigma_{\max }\right)$ principal stresses were calculated using the following equations:

$$
\begin{aligned}
& \sigma_{\min }=\frac{E}{1-v^{2}}\left(\varepsilon_{\min }+v \varepsilon_{\max }\right)=\frac{E}{2}\left[\frac{\varepsilon_{1}+\varepsilon_{2}}{1-v}-\frac{1}{1+v} \sqrt{2\left\{\left(\varepsilon_{1}-\varepsilon_{3}\right)^{2}+\left(\varepsilon_{2}-\varepsilon_{3}\right)^{2}\right\}}\right], \\
& \sigma_{\max }=\frac{E}{1-v^{2}}\left(\varepsilon_{\max }+v \varepsilon_{\min }\right)=\frac{E}{2}\left[\frac{\varepsilon_{1}+\varepsilon_{2}}{1-v}+\frac{1}{1+v} \sqrt{2\left\{\left(\varepsilon_{1}-\varepsilon_{3}\right)^{2}+\left(\varepsilon_{2}-\varepsilon_{3}\right)^{2}\right\}}\right] .
\end{aligned}
$$




\section{Results and discussion}

\section{Temperature and moisture}

There were no significant changes in the temperature, and sensors managed to measure the temperature without any problems throughout the tests.

In all the tests moisture increased, most significantly in test 5 and least significantly in test 9 (Fig. 5). Changes presented a reaction of the sandy silt to the loading when the air was extruded from the pores. As pores in the soil were filled with either air or water, a lower proportion of air resulted in a higher proportion of water and thus higher moisture. Most significant changes in test 5 probably occurred due to the use of a protective layer and high applied force, causing high stress, air extrusion, soil compaction, and increase in moisture. Also, the protective layer contained some water, which penetrated into the sandy silt during loading and further increased its moisture. Least significant changes in test 9 are most likely a consequence of lower initial moisture and preconsolidation process, making the layer less porous and compressible. A comparison between monotonous and dynamic loading showed a sharper, stepwise increase in the latter. However, moisture changes were mainly conditioned by an increase in the applied force (rapid growth with increasing force) and less by vibrations (absence of significant additional changes when vibrations were applied).

\section{Soil compaction}

During loading, soil compacted due to the extrusion of air and water from the pores. The pore pressure dropped, and the load was transferred to the solid particles, which moved into a denser structure, causing soil compaction (Das and Sobhan 2013: 364-365). Compaction of sandy silt was higher in comparison to gravel, as the latter is coarse-grained and thus less compressible than the former. Additionally, monotonic loading caused more changes in the sandy silt while dynamic in gravel, indicating that higher force had more impact on the more compressible sandy silt while vibration on the less compressible gravel (Fig. 6). This can be explained with the compaction of coarse-grained soil being optimal when a combination of pressure and vibration is applied. In coarse-grained soils, the pressure itself merely increases the effective stresses and thus the friction between the solid particles of the soil, which makes movements of the particles difficult. Vibrations reduce friction between particles and facilitate their movement into a denser structure. In fine-grained soils, compression is conditioned by pressure and kneading, while vibrations merely increase the water pore pressure (Briaud 2013: 701). Worth mentioning is test 9 , in which compaction was small, most likely due to pre-consolidation already causing some naturally occurring, gravity and water draining induced compression. Interestingly protective layer in some of the tests increased compaction, most significantly when vibrations were applied. This indicates that the additional weight of the protective layer in combination with vibrations increases soil compaction.

Figure 5. Moisture changes.

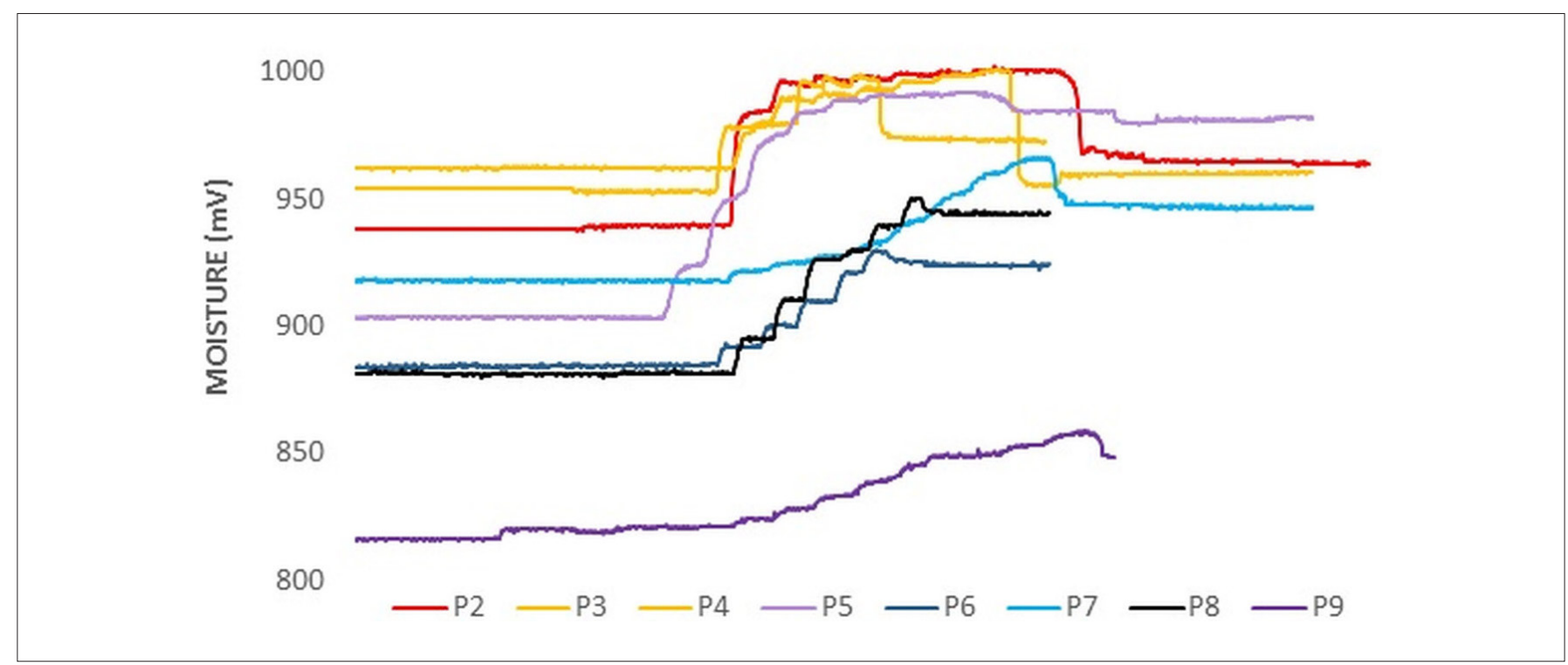




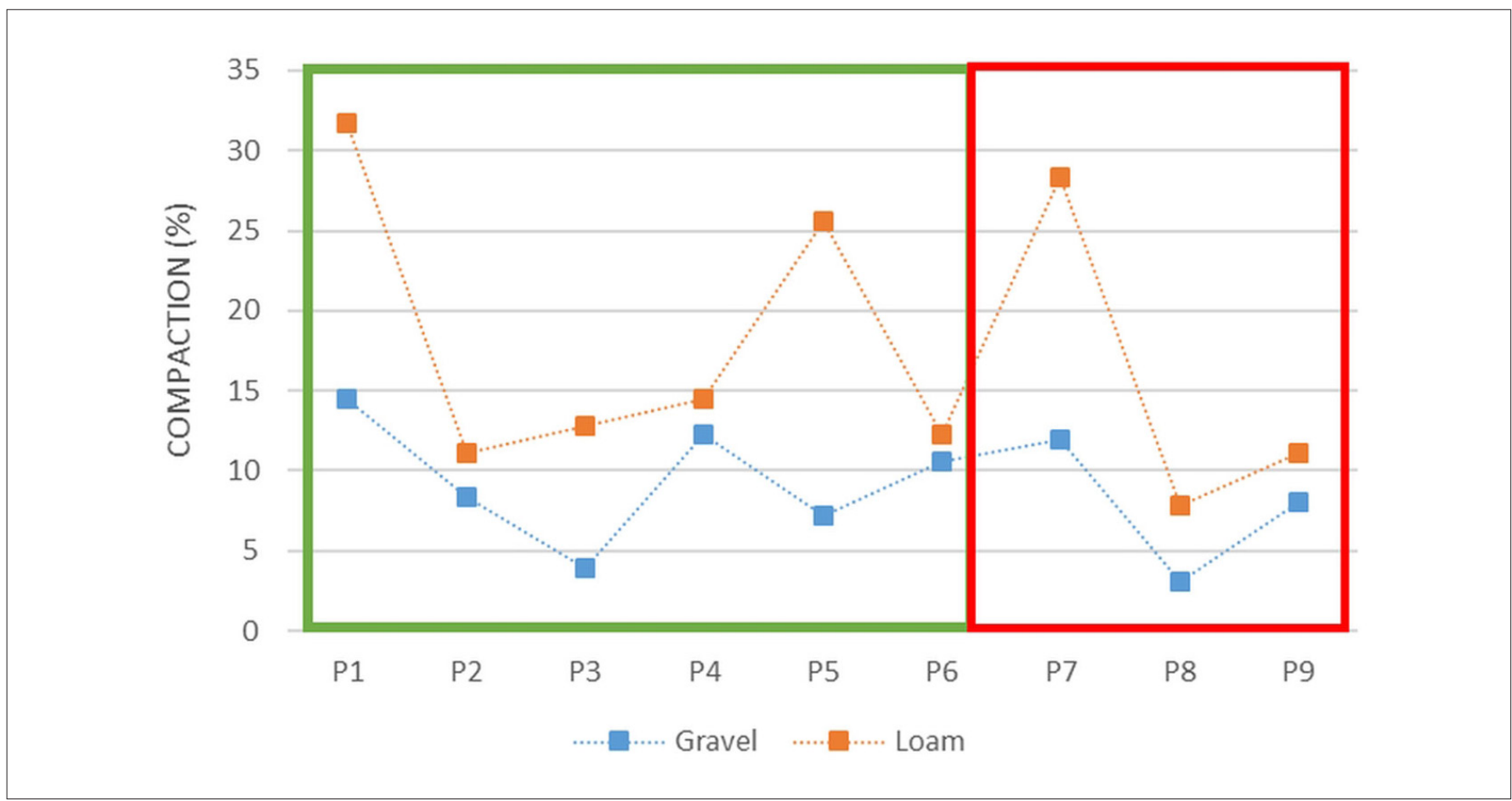

Figure 6. Compaction of gravel (blue) and loam (orange) due to loading.

\section{Soil compressibility}

Constrained modulus (M) increased after loading, making the soil less elastic and more compressed. Since modulus reflects the resistance of a substance to compression and is defined by the ratio between the change in pressure and volume, its increase was expected. However, the significance of its changes differed based on the moisture and presence of vibrations. In general, higher soil moisture and the use of protective layer lead to less compression than lower soil moisture and lack of protective layer.

\section{Stress in the soil}

Changes in the soil stress are consistent with the magnitude of the applied force. They were the lowest in the cases of dynamic loading (tests 3, 6 and 8), and highest in the cases of monotonic loading with a protective layer (tests 1 -6). Additionally, the observed lower increase in stress in gravel could be attributed to a decrease in the impact of loading with increasing depth (Sohne and Soehne 1958; Das and Sobhan 2013: 166). Comparisons with the results of the study carried out by Godwin et al.
(2009: Appendix 1) show that calculated total stresses during loading are similar to the stresses at a depth of $0.25 \mathrm{~m}$ caused by a plough and a heavy roller $(25 \mathrm{kPa}$ $-30 \mathrm{kPa}$ ), and a five-ton combine on tracks or five-ton combine with tires with an air pressure of 1 bar $(50 \mathrm{kPa}$ $-80 \mathrm{kPa}$ ). At greater depths, between $0.55 \mathrm{~m}$ and 0.65 $\mathrm{m}$, similar stress ( $50 \mathrm{kPa}-80 \mathrm{kPa}$ ) is caused by a two-ton tractor, and a five- and ten-ton combine with tires with an air pressure of $1-2$ bar (Godwin et al. 2009: Appendix 1: 16-19).

\section{Displacement and damage}

In test 1-3, only wooden specimens were used, placed in the sandy silt either vertically or horizontally. The results show that there was more displacement of horizontally placed specimens than of vertically placed specimens. Furthermore, the displacement of horizontally placed specimens was more dependent on the magnitude of the applied force and less on vibrations. In contrast, the opposite is true for the displacement of vertically placed specimens (Fig. 7). 


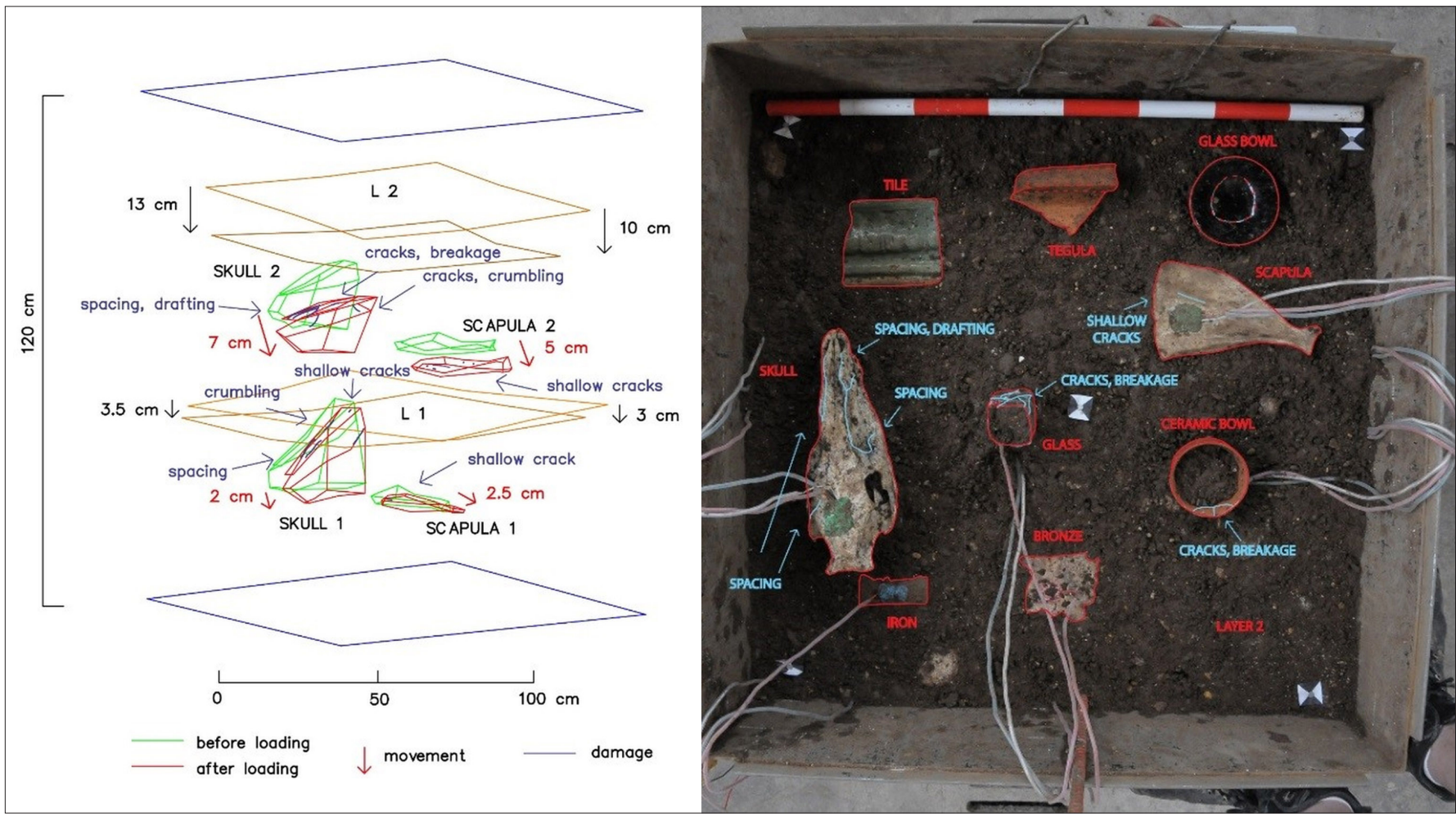

Figure 7. Schematic presentation of artefact displacement and damage due to loading (left) and partially excavated artefacts in loam with marked damage caused by loading (right).

In tests $4-9$, where other materials were used, the average displacement in the sandy silt was approximately twice as large as in gravel. Additionally, higher moisture and lack of protective layer in monotonic tests increased the displacement. At the same time, the impact of vibrations was unpredictable and more severe in the case of the protective layer. On the other hand, lower moisture and pre-consolidation limited the displacement, most likely on account of lower porosity and denser structure of the soil.

With wooden artefacts, damage mainly presented as surface abrasions or small cracks, only in one case artefact broke. On average, the magnitude of the force had

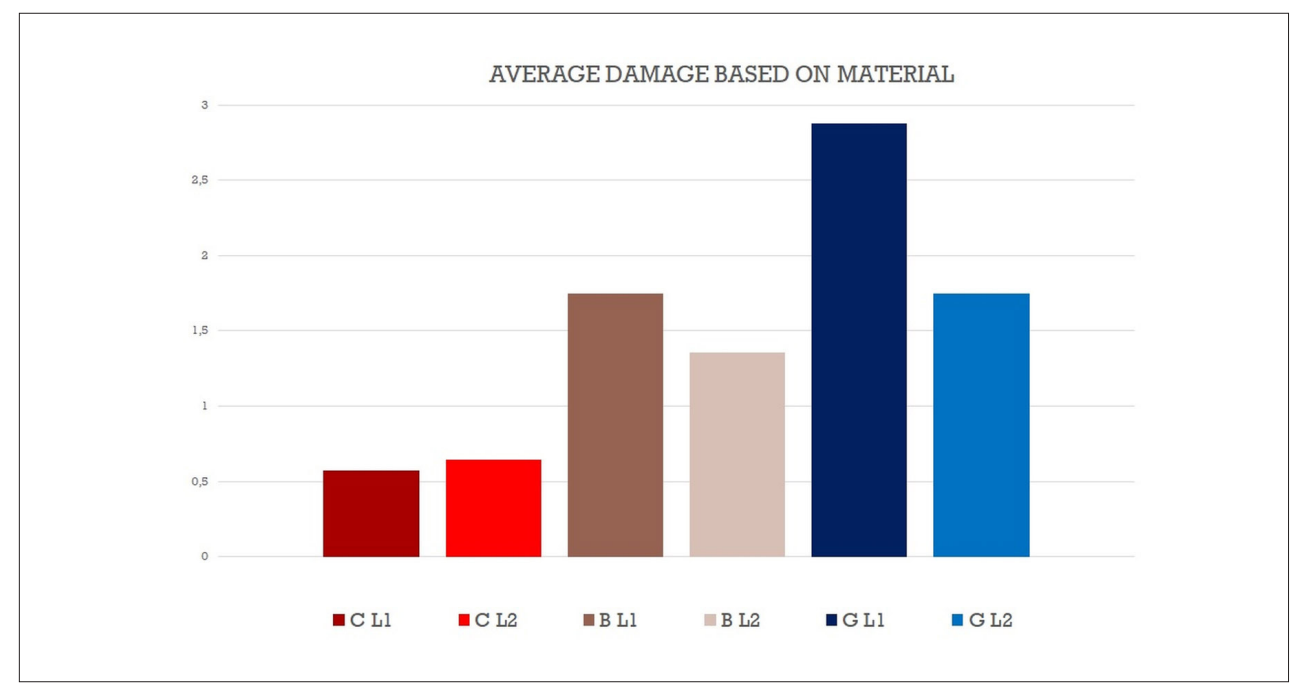

Figure 8. Average damage of different artefacts in gravel and sandy silt ( $\mathrm{C}$ = ceramic; $\mathrm{B}=$ bone; $\mathrm{G}$ = glass; $\mathrm{L} 1$ = gravel; $\mathrm{L} 2$ sandy silt). 
more impact on the damage than vibrations, and vertically placed artefacts suffered more damage than horizontally placed artefacts, likely due to the parallel orientation of the latter and perpendicular orientation of the former to the surface load. Other materials suffered more damage when placed in gravel than in sandy silt. This was expected as gravel is more coarse, less moist and less compressible, facilitating the transition of stress from the soil particles to the artefacts (Sidell et al. 2004; Booth and Spandl 2009). While higher moisture limited the damage, pre-consolidation and protective layer, especially in combination with vibrations, increased it. Furthermore, an inverse relationship was observed with damage and displacement. The more the artefacts moved, the less damage they suffered.

Considering each material separately, metal artefacts suffered no visually observable damage, while $21.4 \%$ of ceramic, $62.5 \%$ of glass and $64.2 \%$ of bone artefacts did (Fig. 8). However, bone artefacts only obtained small scale damage, such as abrasions, chipped edge and shallow cracks, while ceramic and especially glass artefacts cracked or even broke completely. The damage of the artefacts was consistent with the material they were made of. Metal is extremely resistant and ductile, which means that high stresses are necessary for damage to occur. Fresh bone is also resistant and ductile and needs to be under high stress to break. The frequently occurred, yet small-scale damage in bones can be explained with its irregular, physically pronounced shape.
On the other hand, ceramic and glass are fragile materials, prone to crack. Furthermore, in test 10 all archaeological artefacts broke, while significantly less damage was observed in the modern artefacts. The results clearly highlight that archaeological artefacts are much more fragile than modern ones. This is understandable, as the exposure of the archaeological artefacts to the environment altered their physical, chemical and biological characteristics, weakening their structure and resistance to stress (Boskey et al. 1999; van der Meulen et al. 2001).

\section{Stress and strain}

In tests 4-9, compressive and tensile stresses and strains were recorded on the artefacts, reflecting their shrinkage, elongation and breakage (Fig. 9). Due to applying compressive force, compressive stresses and strains prevailed. The exception is bone artefacts. In scapulae, equal presence of compressive and tensile stresses and strains was observed, probably due to their flat shape. In the skulls, compressive stresses with tensile deformations were observed, indicating flexion of the skull, probably due to its physically pronounced and hollow shape. Even though there are too many variables for the recorded stresses and strains, and deformations of the artefacts to be directly correlated to a specific condition and/or loading, some patterns were observed. The pro-
Figure 9. An example of the results obtained with straingauges placed on the ceramic bowl in gravel and sandy silt during loading and unloading of the artificial archaeological site. The blue and red lines represent strain in the bowl in gravel, which only suffered minimal damage (chipped edge), while the grey and purple of strain in the bowl in sandy silt, which cracked right under the strain gauge.

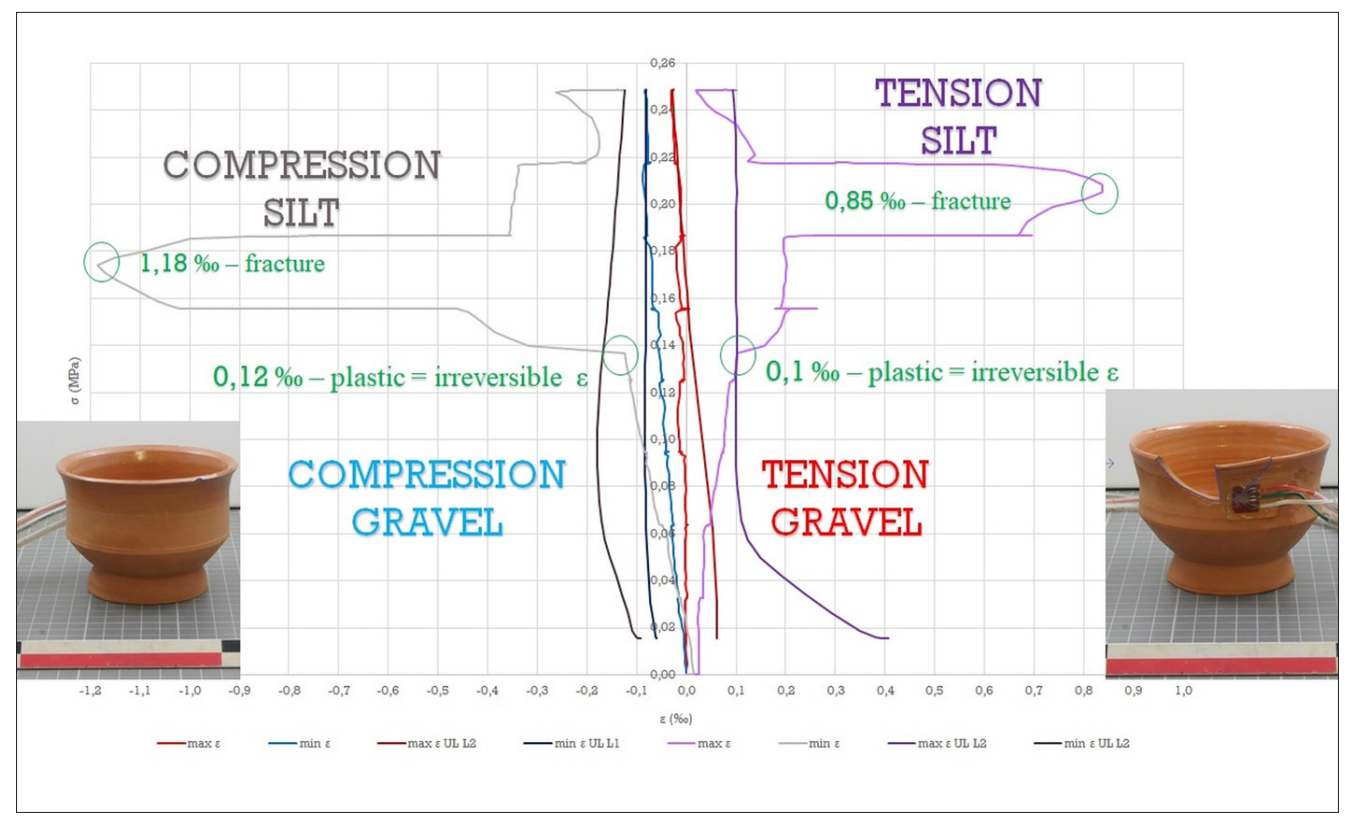


tective layer caused higher stresses, deformations and damage (negative impact) in bronze, iron and bone artefacts in gravel and smaller (positive impact) in sandy silt. The exception is bone artefacts in dynamic tests, where stresses, deformations, and damage were greater in the sandy silt. In ceramic artefacts, the protective layer reduced stresses, deformations and damage of the artefacts (positive impact) in gravel, while increased them (negative impact) in sandy silt. In the case of glass, the protective layer increased stresses, deformations and damage to the artefacts (negative impact) in the gravel and sandy silt. The comparison between the impact of force magnitude and vibration shows that the vibrations caused greater stresses, deformations and damage in bronze artefacts in gravel, bone artefacts in gravel and glass artefacts in gravel and sandy silt. In the remaining cases, the magnitude of the force had a higher impact, causing higher stresses, deformations and damage. Preconsolidation reduced stresses, deformation, and damage in most artefacts (positive impact). The exception is bone artefacts in gravel and glass artefacts in gravel and sandy silt, where pre-consolidation caused higher stresses, deformation and damage (negative impact).

\section{Conclusion}

The results of the tests present significant changes in moisture due to additional surface loads, a connection between the soil compaction and displacement of artefacts, and an increase in damage when the displacement of artefacts is limited. An unpredictable and negative impact of vibrations was also observed, especially when using the protective layer. Although somewhat simplified, the results of the strain gauges and macroscopic damage on the artefacts (bone, ceramics, glass) are consistent. The highest deformations were recorded in the artefacts in the gravel in tests 6, 8 and 9 and the sand silty in tests 5 and 6 . Average macroscopic damage of the artefacts was highest in the sandy silt in tests 5 , 6 and 9 and the sandy silt in tests 5 and 6 . With highest deformations and macroscopic damage in tests 5, 6 and 9 , the negative impact of the protective layer and vibrations was confirmed, especially in the case of their combination, and the negative impact of soil pre-consolidation. Differences were also observed between relatively elastic, solid or thick-walled metal and bone artefacts and brittle, hollow and thin-walled ceramic and glass artefacts. Deformations and macroscopic damage of the former were most dependent on the vibrations and the type of soil in which they were buried while the latter on the magnitude of the force applied to the surface of the site.

The results of this study are not sufficient to produce reliable values of stresses and strains within which the artefacts are safe from damage caused by additional surface loads. The simplification of extremely complex situations occurring in real cases was simply too great. Also, the soil has a pronounced and unpredictable effect on the measurements and behaviour of the artefacts, a good understanding of which would require additional tests. Nevertheless, some useful data were obtained. The metal artefacts were not damaged in any of the tests. The bone artefacts suffered various, minor damages, but only the bones from archaeological contexts broke. However, the transition to nonlinear deformations in modern bone artefacts was observed and should not be neglected as it indicates that deformations approached limits when permanent damage of the bone structure occurs. Ceramic and glass artefacts suffered the most damage, in some cases even broke completely. The stresses in the ground that caused damage of the artefacts are comparable to the stresses caused by a heavy roller and a five-ton combine on caterpillars or tires with an air pressure of 1 bar at $0.25 \mathrm{~m}$, while at greater depths, between $0.55 \mathrm{~m}$ and $0.62 \mathrm{~m}$, comparable stresses in the ground are caused by a $2 t$ tractor and a $5 t$ and $10 t$ combine with tires with an air pressure of 1-2 bar (Godwin et al. 2009: Appendix 1: 16-19).

Regarding the protective layer, Avsenik (2012: 76, 124) mentions that in the absence of artefacts in the upper $50 \mathrm{~cm}$ of the ground, the protective layer is not recommended as its construction and additional weight causes excessive soil deformation and could damage the artefacts deeper in the ground. The present study showed that the use of a protective layer could do more harm than good. When considering the protective layer, in addition to its own weight and the depth of the remains, it is also necessary to take into account the physical properties of the soil and the types of artefacts present in the soil. The grain size and moisture of the soil have a strong impact on the plasticity and bearing capacity of the soil. At the same time, the type of material and the state of preservation determine the mechanical properties of the artefacts and thus their response to mechanical loads. In the performed tests, ceramic and glass artefacts were the most sensitive to mechanical loading, which is consistent with their mechanical properties and hollow, more pronounced 3D geometric shape. The orientation of the artefacts should not be neglected either, 
as Dain-Owens and co-workers report (2009: Appendix 2: 28 ) that the most prone to damage are the artefacts, which lie perpendicular to the direction of the loading force.

In addition to damage, it is necessary to consider the displacement of the artefacts and the compaction and compression of the soil. They can cause changes in the environment, such as a decrease or rise in moisture, in the stratigraphy of the site and/or to the context of the archaeological remains. In our tests, the less compressible gravel compacted for up to $8 \mathrm{~cm}$, while the more compressible sandy silt up to $20 \mathrm{~cm}$. On average, the artefacts in gravel moved for $5 \mathrm{~cm}$ and in sandy silt for $9 \mathrm{~cm}$. It should be noted that most of the tests were performed in poorly consolidated soil, but even after a longer, 4-month consolidation, both type of soils still compacted for $5 \mathrm{~cm}$, and the artefacts moved for 1.5 $4 \mathrm{~cm}$. Furthermore, it is necessary to understand that the spatial distribution of soils and artefacts in the site was artificial and thus uniform. Archaeological sites are characterized by diversity in the dimensions and spatial distribution of different soils and types of the remains. Thus, different compaction of soil with different properties and an additional impact on the stratigraphy and/ or context of the remains is expected (Huisman 2012: 64-66). Also, the mechanical load caused changes in the soil structure and moisture that could increase further in the long run. The denser position of solid soil particles means lower porosity and thus lower humidity and/ or limited water flow through the soil. It also cannot be overlooked that the loading of the site was only performed once. In a study by Goodwin et al. (2009: Appendix 1: 24), cyclic loading caused a $10 \%$ increase in soil stress, meaning that cyclical loads would cause additional changes. Based on the obtained results, it can be deduced that previously proposed theories on better stress transfer from coarse-grained soil to the artefacts compared to transfer from fine-grained soil (Sidell et al. 2004; Booth and Spandl 2009) and decreasing impact of loading with depth (Das and Sobhan 2013: 169) are too simplistic. It is necessary to acknowledge all environmental factors, physical properties of the soils and the properties of the materials present. The proper understanding of the mechanical loading of the surface on the buried archaeological remains requires a complex preliminary study, based on the characteristics of the soils and materials present at the site and additional simulations and/or tests. 


\section{References}

Avsenik, L. 2012. Varovanje arheoloških najdišč in situ s prekrivanjem: diplomska naloga.

Booth, P. and Spandl, K. 2009. Trails to identify Soil Cultivation Practices to Minimise the Impact on Archaeological Sites - BD1705, United Kingdom, Department for Environment, Food and Rural Affairs, English Heritage.

Boskey, A. L., Wright, T. M. and Blank, R. D. 1999. Collagen and Bone Strength, Journal of Bone and Mineral Research 14, 330-335.

Briaud, J. L. 2013. Geotechnical engineering: unsaturated and saturated soils, John Wiley \& Sons, New Jersey.

Council of Europe, V. T. 1992. Chart of signatures and ratification of Treaty 143. European Convention on the Protection of the Archaeological Heritage (Revised).

Darvill, T. and Fulton, A. K. 1998. MARS: the monuments at risk survey of England, School of Conservation Sciences, Bournemouth University.

Das, B. M. and Sobhan, K. 2013. Principles of geotechnical engineering, Cengage Learning, Stamford.

de Lange, G., Bakr, M., Gunnink, J. L. and Huisman, D. J. 2012. A predictive map of compression-sensitivity of the Dutch archaeological soil archive, Conservation and Management of Archaeological Sites 14, 284-293.

Garfinkel, A. P. and Lister, B. L. 1983. Effects of high embankment construction on archaeological materials, State of California Department of Transportation, Division of Construction, Sacramento.

Godwin, R. J., Dresser, M. L., Blackburn, D. W. K., Hann, M. and Dain-Owens, A. P. 2009. Sub-soil Pressures Resulting from Tillage Implements and Vehicle Loads, In: P. Booth and K. Spandl (eds.), Trials to Identify Soil Cultivation Practices to Minimise the Impact on Archaeological Sites, Oxford Archaeology and Cranfield University, Oxford, Appendix 1.

Groenewoudt, B. J. and Bloemers, J. H. F. 1997. Dealing with Significance: Concepts, Strategies, and Priorities for Archaeological Heritage Management in the Netherlands, In: W. J. Willems, H. Kars and H., D. P. Hallewas (eds.), Archaeological Heritage Management in the Netherlands, Assen, Van Gorcum, 119-172.
Huisman, D. J. 2009. Degradation of Archaeological Remains, Sdu Uitgevers, Den Haag, Netherlands.

Hyde, A. 2004. Damage to inclusions in sand subjected to one-dimensional compression, In: T. Nixon (ed.), Preserving Archaeological Remains in Situ? Proceedings of the 2nd Conference, 12-14th September 2001, Museum of London Archaeology Service, 32-39.

Mathewson, C. C., Gonzalez, T. and Eblen, J. S. 1992. Burial as a method of archaeological site protection, A\&M University, Austin, Texas.

McGowan, G. and Prangnell, J. 2015. A method for calculating soil pressure overlying human burials, Journal of Archaeological Science 53, 12-18.

Olson, J. R. 1989. Soil-Structure Interaction Testing for Assessing the Impact of Pipe Laying Operations at the Kaufmann II Archaeological Site, Unpublished report to Texas Eastern Gas Pipeline Company, Battelle, Columbus Division.

Olson, R. J., Guerrieri, D. D. and Jones, D. J. 1988. The Impact of Pipe Lying Operations on the Kauffman II Archaeological Site, Report prepared for Texas Eastern Gas Pipeline Company by Battelle, Columbus Division: Columbus, $\mathrm{OH}$.

Sidell, E. J., Higuchi, T., Allison, R. J. and Long, A. J. 2004. The response of archaeological sediments and artefacts to imposed stress regimes as a consequence of past, present and future anthropogenic activity, In: T. Nixon (ed.), Preserving Archaeological Remains in Situ? Proceedings of the 2nd Conference, 12-14th September 2001, Museum of London Archaeology Service, 42-49.

Sohne, W. and Soehne, W. 1958. Fundamentals of pressure distribution and soil compaction under tractor tires, Agricultural Engineering 39, 290.

van der Meulen, M. C. H., Jepsen, K. J. and Mikić, B. 2001. Understanding bone strength: size isn't everything, Bone 29, 101-104. 